DOI: $10.5216 /$ cab.v14i3.18613

\title{
IDENTIFICAÇÃO DE BACTÉRIAS NO SÊMEN DE OVINOS EM DIFERENTES SISTEMAS DE CRIAÇÃO E O EFEITO DO USO DE KILOL-L ${ }^{\circledR}$
}

\author{
Gabriela de Oliveira Fernandes ${ }^{1}$, Diogo Ramos Leal ${ }^{1}$, Nathalia Hack Moreira ${ }^{1}$, Thiago \\ Antonio de Souza Nascimento Silva ${ }^{1}$, AleXANDRe Floriani Ramos ${ }^{2}$, JaIRo Pereira NeVes ${ }^{3}$ \\ 19ós-Graduandos da Universidade de Brasília, Brasília, DF, Brasil. - diogorleal@ gmail.com \\ ${ }^{2}$ Pesquisador da Embrapa Recursos Genéticos e Biotecnologia, Brasília, DF, Brasil. \\ ${ }^{3}$ Professor da Universidade José do Rosário Vellano, UNIFENAS, Alfenas, MG, Brasil.
}

\section{RESUMO}

O objetivo deste trabalho foi identificar e quantificar as bactérias do sêmen fresco de ovino, avaliar o uso do higienizante Kilol-L ${ }^{\circledR}$ antes da coleta do sêmen e testar a sensibilidade das cepas bacterianas frente ao antibiograma. Foram selecionados 24 ovinos machos, clinicamente sadios, com idade média de quatro anos, da raça Santa Inês, agrupados em dois sistemas de criação: a pasto $(n=12)$ e confinamento $(n=12)$. Dos 120 ejaculados coletados, 99 tiveram crescimento bacteriano correspondendo a $82,5 \%$ das amostras. Os gêneros bacterianos isolados com maior frequência foram Staphylococcus spp., Bacillus spp., Streptococcus spp., Corynebacterium spp., Listeria spp.e Escherichia coli.
Dos antibióticos testados, a amicacina e a gentamicina foram $100 \%$ eficazes para Bacillus spp. e E. coli. O ceftiofur foi efetivo para todas as bactérias isoladas, exceto Rodococcus equi. Streptococcus spp. foram sensíveis à ampicilina e eritromicina, Staphylococcus spp. foram sensíveis à gentamicina. $\mathrm{O}$ uso Kilol-L ${ }^{\circledR}$ reduziu o número de unidades formadoras de colônias (UFC/mL) do ejaculado sem prejudicar a sua qualidade. Dos antibióticos testados, ceftiofur e gentamicina foram os mais efetivos frente às cepas bacterianas isoladas. Dessa forma, a utilização desses antibióticos no meio diluidor do sêmen ovino é uma alternativa para controlar o crescimento bacteriano.

PALAVRAS-CHAVE: antibiograma; bactérias; higienizante; ovinos; parâmetros espermáticos; sêmen.

\section{IDENTIFICATION OF BACTERIA IN THE SEMEN IN DIFFERENT BREEDING SYSTEMS AND THE EFFECT OF KILOL-L ${ }^{\circledR}$}

The objective of this study was to identify and quantify bacteria from fresh ram semen, evaluate the use of sanitizer Kilol-L ${ }^{\circledR}$ prior to semen collection, and test the sensitivity of bacterial strains against antibiotics. We selected 24 Santa Inês rams clinically healthy, at 4 years of aged, and grouped them into two systems: on pasture $(n=12)$ and confined $(n=12)$. The microbiological results indicated that of the total of 120 ejaculates, 99 had bacterial growth, representing $82.5 \%$ of the samples. The most frequently isolated bacteria were Bacillus spp., Corynebacterium spp., Escherichia coli, Listeria spp., Staphylococcus spp., and Streptococcus spp. From the tested antibiotics, amicacin and gentamicin were $100 \%$ effective for Bacillus spp. and E. Coli. Ceftiofur was effective for all isolates except for Rodococcus equi. Streptococcus spp. were susceptible to ampicillin and erythromycin and Staphylococcus spp. were sensitive to gentamycin. The use of Kilol-L ${ }^{\circledR}$ reduced the number of 
Colony Forming Units (CFU/mL) from ejaculate without damaging semen quality. From the tested antibiotics, ceftiofur and gentamicin were more effective against the isolated bacterial strains; thus the use of these antibiotics in the ram semen extender is an alternative to control bacterial growth.

KEYWORDS: antibiogram; bacteria; ovine; sanitizer; semen sperm parameters.

\section{INTRODUÇÃO}

Os microrganismos são contaminantes importantes de muitos fluidos orgânicos, incluindo o sêmen de animais e humanos. A contaminação microbiológica é um importante parâmetro a ser considerado no controle de qualidade do sêmen tanto para inseminação artificial (IA) quanto para sistemas de monta natural (MARTÍN et al., 2010). Existem duas principais fontes de contaminação do sêmen, a primeira pode ser originada das fezes, fluidos prepuciais, secreções respiratórias, pele, pelos e contaminação humana, já a segunda pode ser proveniente da água, de copos coletores, de equipamentos e condições deficientes de higiene (ALTHOUSE \& LU, 2005).

Em machos mamíferos, a uretra é parte comum do sistema urinário e genital, consequentemente a contaminação do sêmen, pode ter origem em ambos os sistemas. Bactérias infectando o trato urinário expressam fatores de virulência que permitem a colonização e dano tecidual, provocando bacteriúria assintomática, cistite ou pielonefrite (JOHNSON, 1991).

Ao longo dos anos, pesquisas vêm sendo realizadas para identificar os agentes que podem ser transmitidos por meio do sêmen e os pontos críticos na coleta e processamento do ejaculado. Dessa maneira, o sêmen utilizado na IA não deve oferecer riscos de transmissão de enfermidades. Apesar de as centrais de coleta e processamento de sêmen adotarem sistematicamente medidas higiênicas para a manipulação e preparo do sêmen, a presença de bactérias não será evitada nem mesmo com o uso de antibióticos no meio diluidor (ALTHOUSE \& LU, 2005).

Segundo DIEMER et al. (1996), os microrganismos tem efeito deletério na função espermática, tanto alterando diretamente a estrutura destas células, afetando a motilidade ou promovendo reação acrossomática prematura, quanto indiretamente por estimular a produção de anticorpos. A interação de Escherichia coli com os espermatozoides tem sido estudada em diversas espécies (AUROUX et al., 1991), por ter efeito espermicida, além de causar um decréscimo na motilidade das células espermáticas, de aumentar a aglutinação dessas células, como também interferir na longevidade espermática e fertilidade do rebanho (ALTHOUSE et al., 2000).

A motilidade progressiva é um importante parâmetro na avaliação dos espermatozoides, pois é um indicativo da vitalidade, a qual está diretamente relacionada à viabilidade (POPWELL et al., 2004). A aglutinação de células espermáticas tem sido correlacionada com a alta incidência de contaminação bacteriana. Apesar da existência de novos e potentes antibióticos, a resistência tem sido observada nas diferentes amostras de sêmen de varias espécies (ALTHOUSE \& LU, 2005).

O objetivo deste trabalho foi identificar e quantificar as bactérias presentes no sêmen fresco de carneiros mantidos à pasto ou confinados, testar a sensibilidade das cepas bacterianas isoladas frente ao antibiograma e avaliar o uso do higienizante Kilol-L ${ }^{\circledR}$ (Quinabra, São Paulo, Brasil) na cavidade prepucial antes da coleta do sêmen.

\section{MATERIAL E MÉTODOS}

Foram selecionados 24 carneiros da raça Santa Inês clinicamente sadios, com escore corpóreo 3 (1-5), idade média de 4 anos, aptos à reprodução e com características espermáticas acima dos padrões mínimos preconizados pelo Colégio Brasileiro de Reprodução Animal CBRA (1998). Os animais permaneceram alojados na Fazenda Experimental Sucupira da Embrapa Recursos Genéticos e Biotecnologia.

Os animais foram distribuídos em dois grupos. Um grupo foi mantido em sistema de confinamento $(n=12)$ com livre acesso à água e sal mineral (SupraSalovinos ${ }^{\circledR}, \quad$ contendo na composição cálcio, fósforo, sódio, magnésio, enxofre, iodo, manganês, selênio, cobalto, molibdênio, zinco e flúor), e foi alimentado com feno Tifton, silagem de milho e ração completa de $16 \%$ de proteína bruta para ovinos tipo carne 
$\left(\right.$ Supra $\left.{ }^{\circledR}\right)$. O outro grupo foi mantido a pasto $(\mathrm{n}=12)$, teve livre acesso à água e sal mineral e foi alimentado com pastagem de Tifton e silagem de milho.

As coletas foram realizadas com vagina artificial (EVANS \& MAXWELL, 1987), quinzenalmente, até completarem cinco repetições (60 ejaculados por grupo), no período de janeiro a maio de 2011, e todo o material utilizado para a coleta e processamento foi previamente esterilizado. Nas duas primeiras coletas de cada grupo, foi realizada higienização da região externa do prepúcio com sabão neutro e solução salina $0,9 \%$, nas três últimas foi utilizado o higienizante Kilol-L ${ }^{\circledR}$ (concentração 1:250) na cavidade prepucial. Cada ejaculado foi separado em duas alíquotas, uma para a análise do sêmen e outra para a avaliação bacteriana.

Os parâmetros do sêmen avaliados foram: volume (mL), motilidade (\%), vigor (1-5) e concentração (CBRA, 1998). Para a avaliação microbiológica, amostras de cada ejaculado foram armazenadas individualmente em microtubos autoclavados, mantidas sob refrigeração e encaminhadas ao Laboratório de Microbiologia Veterinária da Universidade de Brasília, para a realização da contagem de unidades formadoras de colônia (UFC/mL) e identificação das colônias bacterianas.

Para o processamento das análises microbiológicas, $100 \mu \mathrm{L}$ do sêmen puro de cada amostra foi diluído em $9,9 \mathrm{~mL}$ de solução salina estéril. Cada amostra foi distribuída em placas petri para a adição do agar padrão para contagem bacteriana total (PCA, Himedia ${ }^{\circledR}$ ) e incubadas a $37^{\circ} \mathrm{C}$ por $24 \mathrm{~h}$. As amostras também foram estriadas em agar sangue ovino $5 \%$ e incubadas a $37^{\circ} \mathrm{C}$ por 24 e $48 \mathrm{~h}$ para verificação do crescimento bacteriano. Nas amostras que apresentaram crescimento, foram observadas as características morfotintoriais e classificadas em gram positivas ou negativas, cocos ou bastonetes, também foram realizados testes complementares (catalase, fermentação/oxidação, oxidase, descarboxilase, indol, motilidade, urease) para a identificação das bactérias.

O antibiograma foi realizado pelo método de difusão por disco. Para isso, as colônias bacterianas identificadas foram previamente inoculadas no caldo Muller-Hinton (Himedia $^{\circledR}$ ), incubadas a $37^{\circ} \mathrm{C}$ até atingirem a turbidade de 0,5 da escala de McFarland; em seguida, um swab estéril foi utilizado para semear o caldo na superfície do agar Muller-Hinton (Himedia ${ }^{\circledR}$ ) em placa petri, seguido da distribuição dos discos impregnados de antibióticos (amicacina, ampicilina, ceftiofur, eritromicina, estreptomicina, gentamicina, lincomicina, penicilina e polimixina B). As placas foram incubadas a $37^{\circ} \mathrm{C}$ por 18 horas, quando foram realizadas as leituras $\mathrm{e}$ interpretações dos halos de inibição. As bactérias foram classificadas em sensíveis, intermediárias ou resistentes.

Os dados obtidos foram avaliados por análise de variância (ANOVA), empregando-se o programa estatístico SAS (Statistical Analyses System, versão 9.0, 2002), com significância de $\mathrm{p}<0,05$.

\section{RESULTADOS E DISCUSSÃO}

Os resultados microbiológicos indicaram que, do total de 120 ejaculados, 99 tiveram crescimento bacteriano, correspondendo a $82,5 \%$ das amostras. Os gêneros bacterianos isolados com maior frequência foram Bacillus spp., Corynebacterium spp., Escherichia coli., Listeria spp., Staphylococcus spp. e Streptococcus spp.. Os mesmos gêneros foram isolados em ovinos por YÁNIZ et al. (2010), em caprinos por SOUZA et al. (2006), em bovinos por PRADO et al. (2005), em bubalinos por AKHTER et al. (2008), em suínos por ALTHOUSE \& LU (2005) e em equinos por BRISTOL (1991).

$\mathrm{O}$ gênero bacteriano mais isolado no grupo confinado foi Bacillus spp. (23,65\%), enquanto nos animais a pasto foi Staphylococcus spp. $(46,15 \%)$ (Tabela 1). Houve diferença $(\mathrm{p}<0,05)$ no isolamento de E. coli, Bacillus spp. e Listeria spp. no grupo confinado quando comparado com o grupo à pasto.

No presente estudo, dos nove antibióticos testados in vitro, o ceftiofur e a gentamicina foram os que apresentaram maior eficiência frente às 132 cepas bacterianas isoladas do sêmen fresco ovino (Tabela 2), o que corrobora os achados de YÁNIZ et al. (2010); no entanto, são necessários estudos que determinem seu efeito na função espermática. 
TABELA 1 - Porcentagem das cepas bacterianas isoladas do sêmen de ovinos da raça Santa Inês criados a pasto e confinados

\begin{tabular}{lcc}
\hline Bactérias isoladas & Confinado $(\%)$ & Pasto $(\%)$ \\
\hline Acinetobacter calcoaceticus & $3,22^{\mathrm{a}}$ & $12,82^{\mathrm{a}}$ \\
Bacillus spp. & $23,65^{\mathrm{a}}$ & $2,56^{\mathrm{b}}$ \\
Corynebacterium spp. & $17,21^{\mathrm{a}}$ & $12,82^{\mathrm{a}}$ \\
Enterobacter spp. & - & 2,56 \\
Escherichia coli & $9,68^{\mathrm{a}}$ & $7,70^{\mathrm{b}}$ \\
Listeria spp. & $10,75^{\mathrm{a}}$ & $5,13^{\mathrm{b}}$ \\
Staphylococcus spp. & $18,28^{\mathrm{a}}$ & $46,15^{\mathrm{a}}$ \\
Streptococcus spp. & $17,21^{\mathrm{a}}$ & $7,70^{\mathrm{a}}$ \\
Rodococcus equi & - & 2,56 \\
\hline a,b Valores percentuais seguidos por letras minúsculas na mesma linha diferem entre si $(\mathrm{p}<0,05)$.
\end{tabular}

TABELA 2 - Antibiograma das 132 cepas bacterianas isoladas do sêmen de ovinos da raça Santa Inês em manejo a pasto e confinados

\begin{tabular}{lccc}
\hline Antibióticos & Resistente $\%$ & Intermediário \% & Sensível \% \\
\hline Amicacina $(30 \mu \mathrm{g})$ & 12,88 & 0,76 & 86,36 \\
Ampicilina $(10 \mu \mathrm{g})$ & 25,76 & 3,79 & 70,45 \\
Ceftiofur $(30 \mu \mathrm{g})$ & 0,76 & 0,76 & 98,48 \\
Estreptomicina $(10 \mu \mathrm{g})$ & 17,43 & 6,82 & 75,75 \\
Eritromicina $(15 \mu \mathrm{g})$ & 15,91 & 12,13 & 71,96 \\
Gentamicina $(10 \mu \mathrm{g})$ & 4,54 & 2,28 & 93,18 \\
Lincomicina $(2 \mu \mathrm{g})$ & 21,21 & 0,76 & 78,03 \\
Penicilina $(10 \mu \mathrm{g})$ & 41,66 & 3,04 & 55,30 \\
Polimixina B $(300 \mu \mathrm{g})$ & 2,28 & 12,88 & 84,84 \\
\hline
\end{tabular}

Dos antibióticos testados, a amicacina e a gentamicina foram 100\% efetivas para Bacillus spp. e E. coli. O ceftiofur foi efetivo para todas as bactérias isoladas, exceto para Rodococcus equi. Bactérias do gênero Streptococcus spp. foram sensíveis à ampicilina e eritromicina e as do gênero Staphylococcus spp. foram sensíveis à gentamicina. Corynebacterium spp. foram consideradas sensíveis a todos os antibióticos testados.

Escherichia coli, quando presente nos ejaculados, normalmente, apresenta efeito inibitório na motilidade das células espermáticas, bem como provoca aglutinação e danos ultraestruturais na membrana dos espermatozoides. Neste estudo, as bactérias E. coli isoladas não promoveram alterações significativas nos parâmetros avaliados do sêmen. A ausência de alterações no sêmen provocadas por essas bactérias corrobora os estudos de ALTHOUSE et al. (2000), que estabeleceram que o efeito deletério da bactéria no sêmen por $E$. coli é concentração-dependente.

As cepas de E. coli isoladas foram resistentes à lincomicina e à penicilina e sensíveis à gentamicina, amicacina e ceftiofur, corroborando os resultados de DRUMMOND (2011). Sobre sêmen de suínos, ALTHOUSE et al. (2000) relataram que as cepas isoladas de E.coli foram resistentes a oito dos dez antibióticos testados e sensíveis apenas ao ceftiofur e à eritromicina.

A contaminação bacteriana do sêmen de ovinos ocorre durante a coleta e processamento e, para minimizar a presença de bactérias no ejaculado, podem-se utilizar agentes higienizantes. A utilização do higienizante kilol- $\mathrm{L}^{\circledR}$ na cavidade prepucial antes da coleta, na concentração 1:250, proporcionou redução significativa $(\mathrm{p}<0,05)$ na quantidade bacteriana total do ejaculado sem alterar os parâmetros avaliados do sêmen, demonstrando, assim, a eficácia do uso de higienizantes no preparo dos animais para a coleta de sêmen.

As unidades formadoras de colônias presentes no ejaculado são um indicador das normas de higiene adotadas na coleta do sêmen. Nas condições em que o experimento foi realizado, observou-se uma média de $6,7 \times 10^{3} \mathrm{UFC} / \mathrm{mL}$, enquanto YÁNIZ et al. (2010) observaram nos ejaculados comerciais de ovinos concentrações superiores a $10^{8} \mathrm{UFC} / \mathrm{mL}$. PRADO et al. (2005), analisando sêmen fresco de bovinos, observaram que $74 \%$ das amostras tiveram concentração menor ou 
igual a $1 \times 10^{4} \mathrm{UFC} / \mathrm{mL}$. A recomendação da OIE para sêmen bovinos é de que a contagem bacteriana não exceda $5 \times 10^{3} \mathrm{UFC} / \mathrm{mL}$.

As avaliações dos parâmetros do sêmen fresco estão expressas na Tabela 3. Não houve diferença entre os grupos e o tipo de limpeza adotado antes da coleta do sêmen quando avaliado quanto à motilidade, vigor e concentração das células espermáticas.

TABELA 3 - Avaliação do sêmen fresco coletado de ovinos da raça Santa Inês, criados a pasto e confinados

\begin{tabular}{|c|c|c|c|c|}
\hline & \multicolumn{2}{|c|}{ Confinado } & \multicolumn{2}{|c|}{ Pasto } \\
\hline & Sem Kilol-L ${ }^{\circledR}$ & Kilol-L $^{\circledR}$ & Sem Kilol-L ${ }^{\circledR}$ & Kilol-L $^{\circledR}$ \\
\hline $\mathrm{UFC} / \mathrm{mL}$ & $6812,50^{\mathrm{a}}$ & $4344,44^{\mathrm{a}}$ & $4746,66^{\mathrm{a}}$ & $1651,11^{\mathrm{b}}$ \\
\hline Volume (mL) & 1,40 & 1,31 & 1,05 & 1,13 \\
\hline Motilidade (\%) & 66,66 & 65,55 & 65,83 & 65,18 \\
\hline Vigor $(1-5)$ & 3,50 & 3,38 & 3,25 & 3,51 \\
\hline Concentração $\left(\times 10^{6} / \mathrm{mL}\right)$ & 2680,00 & 2981,11 & 2474,16 & 2478,52 \\
\hline
\end{tabular}

${ }^{\mathrm{a}, \mathrm{b}}$ Valores para UFC/mL seguidos por letras minúsculas na mesma linha diferem entre si $(\mathrm{p}<0,05)$.

\section{CONCLUSÕES}

Foi possível observar que os animais do grupo confinado apresentaram um aumento da presença de Bacillus spp., Corynebacterium spp. e Escherichia coli em relação aos animais do grupo a pasto e que o uso do higienizante Kilol-L ${ }^{\circledR}$ na concentração 1:250 reduziu o número de unidades formadoras de colônias (UFC/mL) do ejaculado sem prejudicar a qualidade seminal, independentemente do sistema de criação dos animais.

As bactérias E.coli foram resistentes aos antibióticos lincomicina e penicilina enquanto que as do gênero Coryneobacterium spp. foram sensíveis a todos os antibióticos testados. O ceftiofur e a gentamicina foram os antibióticos mais efetivos frente às cepas bacterianas isoladas, mostrando que a utilização desses antibióticos no meio diluidor do sêmen ovino pode ser eficaz no controle do crescimento bacteriano no sêmen.

A adequada higienização dos equipamentos utilizados para a coleta, do local em que os animais são coletados e a prévia higienização prepucial dos carneiros é determinante para minimizar a contaminação bacteriana nos ejaculados e para a obtenção de amostras de sêmen de melhor qualidade.

\section{REFERÊNCIAS}

AKHTER S.; ANSARI, M. S.; ANDRABI, S. M. H.; ULLAH, N.; QAYYUM, W. Effect of antibiotics in extender on bacterial and spermatozoal quality of cooled buffalo (Bubalus bubalis) bull semen. Reproduction in Domestic Animals. v. 43, p. 272-278, 2008.

ALTHOUSE, G.C., KUSTER, C.E., CLARK, S.G.;
WEISIGER, R.M. Field investigations of bacterial contaminants and their effects on extended porcine semen. Theriogenology, v. 53, p. 1167-1176, 2000.

ALTHOUSE, G. C.; LU, K.G.; Bacteriospermia in extended porcine semen. Theriogenology, v. 63, p. 573584,2005

AUROUX, M. R.; JACQUES, L.; MATHIEU, D.; AUER, $\mathrm{J}$. Is the sperm bacterial ratio a determining factor in impairment of sperm motility: in vitro study in man with Escherichia coli. International Journal of Andrology, v. 14, p. 264-270, 1991.

BRISTOL, F. Bacterial flora of the reproductive tract in stallions. Proc Ann Meeting Soc Theriogenology (2 ${ }^{\text {nd }}$ Ed,.), p. 171-173, 1991.

CBRA. Manual para exame andrológico e avaliação de sêmen animal. Colégio Brasileiro de Reprodução Animal. $2^{\circ}$ Ed. Belo Horizonte: CBRA, 1998. 49p.

DIEMER, T.; WEIDNER, W.; MICHELMAN, H. W.; SCHIEFER, H.-G.; ROVAN, E.; MAYER, F. Influence of Escherichia coli on motility parameters of human spermatozoa in vitro. International Journal of Andrology. v. 19, p. 271-277, 1996.

DRUMMOND, V. O. Detecção de genes de enterotoxinas, caracterização bioquímica e avaliação da sensibilidade a antimicrobianos de Escherichia coli isoladas de suínos hígidos do Distrito Federal. Dissertação de mestrado - Universidade de Brasília/ Faculdade de Agronomia de Medicina Veterinária, 2011. Disponível em: http://hdl.handle.net/10482/9018 Acesso em: 15/03/2011.

EVANS, G.; MAXWELL, W. M. C. Salamon's Artificial Insemination of Sheep and Goats. Australia: Star Printery Pty Ltd, 1987. 194p.

JOHNSON, J. R. Virulence factors in Escherichia coli urinary tract infections. Clinical Microbiology Reviews, 
v. 4, p. 80-128, 1991.

MARTÍN, L. O. M.; MUÑOZ, E. C.; BEECKMANS, S.; et al. Bacterial contamination of boar semen affects the litter size. Animal Reproduction Science, v. 120, p. 95104, 2010.

POPWELL, J. M.; FLOWERS, W. L. Variability in relationships between semen quality and estimates of in vivo and in vitro fertility in boars. Animal Reproduction Science, v. 81, n. 1-2, p. 97-113, 2004.

PRADO, E. A. S.; PÉREZ, R. M. Flora bacteriana del semen de toro antes y depués de la congelación. Revista Electrónica de Veterinaria REDVET. v. 6, no 10, p. 1-8, outubro, 2005. Disponível em http://www.veterinaria.org/revistas/redvet/n101005.html.

SOUZA, A. F.; GUERRA, M. M. P.; COLETO, Z. F.; MOTA, R. G.; SILVA, L. B. G.; LEÃO, A. E. D. S.; SOBRINHO, E. S. N. Avaliação microbiológica do sêmen fresco e congelado de reprodutores caprinos. Brazilian Journal of Veterinary Research and Animal Science, v.43, n.3, p. 329-336, 2006.

YÁNIZ, J.L.; MARCO-AGUADO, M. A.; MATEOS, J. A.; SANTOLARIA, P. Bacterial contamination of ram semen, antibiotic sensitivities, and effects on sperm quality during storage at $15^{\circ} \mathrm{C}$. Animal Reproduction Science, v. 9, p. 122-142, 2010.

Protocolado em: 22 maio 2012. Aceito em: 05 ago. 2013 